\section{Bolting and Growth of Spinacia oleracea L. Can be Altered by Modifying the Photoperiod during Transplant Production}

\author{
Changhoo Chun', Ayumi Watanabe' ${ }^{2}$ Hyeon-Hye Kim³ ${ }^{3}$, and \\ Toyoki Kozai ${ }^{4}$ \\ Department of Bioproduction Science, Faculty of Horticulture, Chiba \\ University, Matsudo, Chiba 271-8510, Japan
}

\author{
Junya Fuse \\ Agricultural Development Department, Taiyo Kogyo Co., Tokyo, 111-0053, \\ Japan
}

Additional index words. closed system, flowering, fluorescent lamps, hydroponics

\begin{abstract}
Spinach (Spinacia oleracea L. cv. Dimple) was chosen to determine whether bolting (i.e., elongation of flower stalks) could be controlled by manipulating the photoperiod during transplant production in a closed system using artificial light. Plants grown under various photoperiods during transplant production were transferred and cultured under natural short photoperiods and artificial long photoperiods. Vegetative growth at transplanting tended to be greater with the longer photoperiod because of the increased integrated photosynthetic photon flux. Bolting initiation reacted qualitatively to a long photoperiod, and the critical photoperiod for bolting initiation was longer than $13 \mathrm{~h}$ and shorter than $15 \mathrm{~h}$. The plants grown under a longer photoperiod during transplant production had longer flower stalks at harvest. The long photoperiod and/or high temperature after transplanting therefore promoted flower stalk elongation. Growing plants under a photoperiod that was shorter than the critical photoperiod during transplant production reduced elongation of the flower stalks, thus there was no loss of market value even though the plants were cultured under a long photoperiod and high temperature for 2 weeks after transplanting.
\end{abstract}

Spinach cultured in spring and summer usually has a greater tendency to bolt (Singhal and Kulkarni, 1998). In general, a long photoperiod causes spinach plants to bolt and to flower (Garner and Allard, 1920; Hartmann et al., 1988). A solution to this problem is to grow cultivars that are less sensitive to photoperiod (Kagawa, 1997), but this limits the number of cultivars that can be supplied to markets during the spring and summer. Generally, oriental cultivars that Japanese and other Asian customers prefer bolt easily and therefore are available only in the winter season.

Manipulation of the photoperiod is commonly used in horticultural crop production

Received for publication 8 Apr. 1999. Accepted for publication 13 Aug. 1999. We thank Katuyoshi Okabe and Akira Yoshie, Taiyo Kogyo Co. for their technical support. The cost of publishing this paper was defrayed in part by the payment of page charges. Under postal regulations, this paper therefore must be hereby marked advertisement solely to indicate this fact.

1'Assistant Professor. E-mail: changhoo@ midori.h.chiba-u.ac.jp

${ }^{2}$ Undergraduate Research Associate.

${ }^{3}$ Postdoctoral Research Associate. Current address: Dept. of Horticulture, Michigan State Univ., East Lansing, MI 48824-1325.

${ }^{4}$ Professor. systems based on the flowering physiology of each crop. Supplementary lighting to extend the photoperiod is popular in flower production (Fredericq, 1964; Salisbury, 1965). Covering plants with an opaque curtain or other physical barrier is the only way to shorten the natural photoperiod. However, if artificial lighting is used for transplant production instead of natural light, the photoperiod can be easily manipulated. Recently, a closed transplant production system that uses only artificial light was introduced, and is expected to have many advantages over the conventional transplant production method with natural light (Kozai, 1998).

Chun et al. (2000) showed that bolting, a major problem for spinach production systems, can be prevented by manipulating the photoperiod and temperature during transplant production using artificial light. Kim et al. (2000) reported that spinach plants began to sense the photoperiod during transplant production, and that flower bud development during this period was enhanced under a longer photoperiod. In this study, the effects of photoperiod during transplant production on the growth and bolting of spinach plants cultured under a natural, short photoperiod and under an artificial, long photoperiod were investigated to determine whether bolting could be controlled.
Transplant production. Five spinach, cv. Dimple, seeds (Sakata Seed Co., Yokohama, Japan) were sown in each cell $(2 \mathrm{~cm}$ in diameter) of transplant production trays (144 cells per tray, $30 \times 60 \mathrm{~cm}$; Taiyo Kogyo Co., Tokyo) that had been filled with 3 g (dry weight) of granules of rockwool (Nichias Co., Tokyo) on 10 Nov. 1998. The trays with seeds were wrapped with nontransparent plastic sheets and placed in a walk-in growth chamber for $3 \mathrm{~d}$ for germination.

The trays with germinated seeds were moved to three transplant production modules $(0.51 \mathrm{~m}$ wide $\times 1.25 \mathrm{~m}$ long $\times 0.42 \mathrm{~m}$ high $)$ in a growth chamber. Each module had eight cool-white fluorescent lamps (FPL55EX-N; Matsushita Electric Industrial Co., Osaka, Japan) and a time switch (TB15601; Matsushita Electric Works, Osaka, Japan). The photoperiods in the three modules were set at 11,13, and $15 \mathrm{~h}$, respectively, and the photosynthetic photon flux $(P P F)$ measured on the trays was $310 \pm 20 \mu \mathrm{mol} \cdot \mathrm{m}^{-2} \cdot \mathrm{s}^{-1}$. Each module also had a ventilating fan (EG-35BSB; Mitsubishi Electric Co., Tokyo). Curtains were placed around each module to exclude light from neighboring modules.

During the transplant production period, the air temperature in each module was maintained at $21 \pm 1{ }^{\circ} \mathrm{C}$ and $19 \pm 1{ }^{\circ} \mathrm{C}$ during the photo- and dark periods, respectively. Irrigation was conducted once a day with commercial nutrient solution (High Tempo; Sumitomo Chemical Co., Tokyo). The solution contained $12.0 \mathrm{mmol} \cdot \mathrm{L}^{-1} \mathrm{NO}_{3}-\mathrm{N}, 0.8$ $\mathrm{mmol} \cdot \mathrm{L}^{-1} \mathrm{NH}_{4}-\mathrm{N}, 30.6 \mathrm{mmol} \cdot \mathrm{L}^{-1} \mathrm{P}, 7.3$ $\mathrm{mmol} \cdot \mathrm{L}^{-1} \mathrm{~K}, 10.2 \mathrm{mmol} \cdot \mathrm{L}^{-1} \mathrm{Ca}$, and 4.2 $\mathrm{mmol} \cdot \mathrm{L}^{-1} \mathrm{Mg}$. The $\mathrm{pH}$ and electrical conductivity (EC) of the nutrient solution were 6.0 and $140 \mathrm{mS} \cdot \mathrm{m}^{-1}$, respectively. At $14 \mathrm{~d}$ after sowing (DAS), the maximum leaf length, shoot fresh weight, and number of leaves of the 15 transplants from each replication were measured.

Culture after transplanting. At 14DAS, the plants were transplanted to: 1) a plastic greenhouse under a short natural photoperiod (ca. $11 \mathrm{~h}$ ) or 2) a growth chamber under a long artificial photoperiod $(16 \mathrm{~h})$. Six treatments were used as a result of combining each of the three photoperiods $(11,13$, and $15 \mathrm{~h}$ ) during transplant production (4-14 DAS) with the two photoperiods (ca. 11 and 16h) from transplanting until harvest. The plants cultured under natural light in the greenhouse were harvested $28 \mathrm{~d}$ after transplanting (DAT), while those cultured under artificial light in the growth chamber were harvested 14 DAT.

Throughout the culture period in the greenhouse, the maximum air temperature was $30{ }^{\circ} \mathrm{C}$, and the minimum was not allowed to drop below $13^{\circ} \mathrm{C}$. The air temperatures during photo- and dark periods in the growth chamber were $34 \pm 1$ and $30 \pm 1{ }^{\circ} \mathrm{C}$, respectively. Modified ebb and flow technique (EFT) (Buwalda et al., 1994) and nutrient film technique (NFT) (Cooper, 1973) hydroponic systems were installed in the greenhouse and the growth chamber, respectively. The plants were placed on planting panels (Taiyo Kogyo 
Co.) with a density of 63 cells $/ \mathrm{m}^{2}$ in both systems. In the EFT system, the supply and draining of the nutrient solution $\left(280 \mathrm{mS} \cdot \mathrm{m}^{-1}\right.$ of EC and pH 6.0) was repeated on a 20-40min cycle, while in the NFT system, the nutrient solution was continuously circulated between the nutrient tank and the culture beds. At harvest, the maximum leaf length, shoot fresh weight, number of leaves, and flowerstalk length of 10 plants in each replication were measured. A completely random design was used with four replications. An analysis of variance (ANOVA) test and Duncan's multiple range test were used to compare means in each treatment.

\section{Results}

Maximum leaf length, average number of leaves per plant, and shoot fresh weight per plant at transplanting all increased significantly with increasing photoperiod during transplant production (Fig. 1).

Maximum leaf length at harvest was shortest when the photoperiod during transplant production was $15 \mathrm{~h}$ and the photoperiod after transplanting was $16 \mathrm{~h}$ (artificial light) (Fig. 2A). Maximum leaf length at harvest was greater in plants grown under natural light with an 11-h photoperiod after transplanting than those grown under artificial light with a 16-h photoperiod. Shoot fresh weight at harvest exhibited the same general trend as did the maximum leaf length at harvest, although the effect of photoperiod during transplant production was nonsignificant (Fig. 2B). Number of leaves per plant at harvest was greatest in the plants grown with the 15 -h photoperiod during transplant production (Fig. 2C). Flower stalk length was zero in plants exposed to 11or 13-h photoperiods during transplant production, then grown under natural light with 11-h photoperiod after transplanting. Flower stalk elongation was promoted by exposure to a 15-h photoperiod during transplant production, regardless of the photoperiod and light source after transplanting (Fig. 2D).

\section{Discussion}

Growth and bolting at transplanting. Since the transplants were normal in color and shape, fluorescent lighting was considered to be suitable for their production. The greater vegetative growth at transplanting with longer photoperiod was probably due to the greater integrated photosynthetic photon flux [IPPF $\left(\mathrm{mol} \cdot \mathrm{m}^{-2} \cdot \mathrm{d}^{-1}\right)$, a product of photoperiod $\left(\mathrm{s} \cdot \mathrm{d}^{-1}\right)$ and $\left.P P F\left(\mu \mathrm{mol} \cdot \mathrm{m}^{-2} \cdot \mathrm{s}^{-1}\right)\right]$, as the $P P F$ was identical in all treatments during transplant production. Kitaya et al. (1998) also reported that the growth of lettuce in a transplant production system using artificial light increased with increasing $I P P F$ when various photoperiods and $P P F$ combinations were used. Prediction and/or control of growth is essential for scheduling transplant production. Because elongation of flower stalks was observed only in plants initially exposed to a 15-h photoperiod, we conclude that bolting was initiated during transplant production.

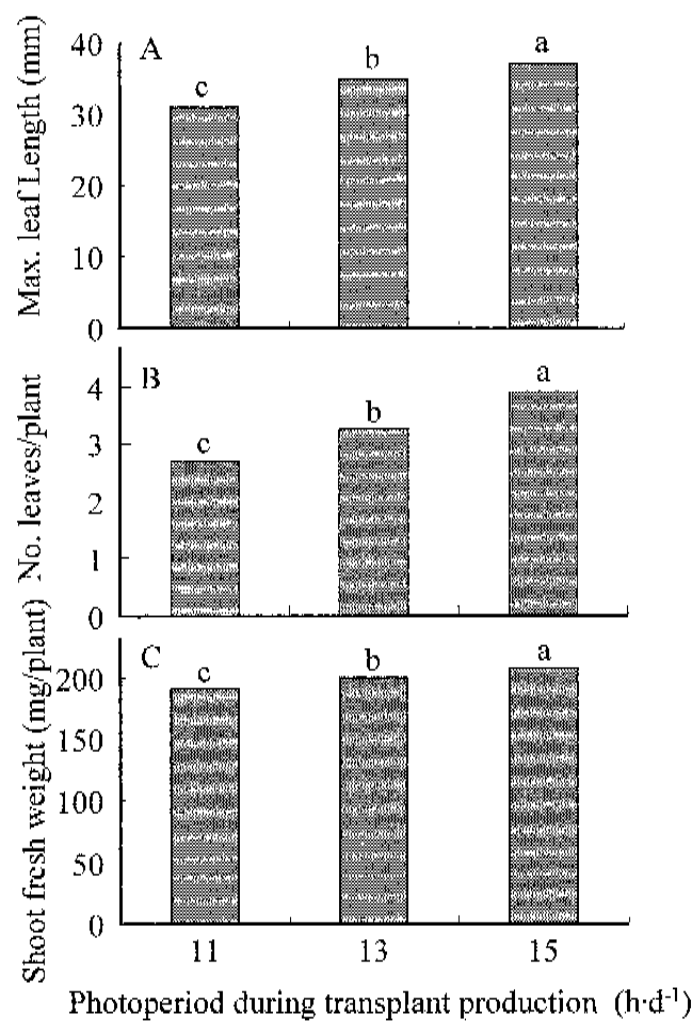

Fig. 1. Effects of photoperiod during transplant production (4-14 DAS) on (A) the maximum leaf length, (B) shoot fresh weight, and (C) number of leaves of spinach transplants at transplanting (14 DAS). Mean separation by Duncan's multiple range test, $P \leq 0.05$.

However, it is not yet clear whether bolting resulted from exposure to a photoperiod that was longer than the critical photoperiod, or progressed regardless of photoperiod but was enhanced by the long photoperiod, as occurred in flower bud development (Eguchi and Ichikawa, 1940).

Growth at harvest. The spinach plants grown in the greenhouse after transplanting could be harvested at a marketable size (ca. $20 \mathrm{~cm}$ of the maximum leaf length) at 28 DAT in the winter season. Chun et al. (2000) harvested the same cultivar with a similar size at 14 DAT in a greenhouse experiment conducted in the summer season. Growth was retarded when plants were grown under artificial light, as air temperatures were high (ca. 34 and $30{ }^{\circ} \mathrm{C}$ during photo- and dark periods, respectively). The roots were brown when harvested.

Bolting at harvest. Spinach is a long-day plant (Boswell, 1935; Kagawa, 1997; Knott, 1932, 1934; Magruder and Allard, 1936; Metzger and Zeevaart, 1980; Zeevaart, 1971). However, the effect of photoperiod on the flowering process is not yet fully understood. Flowering in spinach occurs in several stages: flower bud start, flower bud development, the start of elongation of the flower stalk (bolting), and elongation of the flower stalk. Eguchi and Ichikawa (1940) reported that flower bud start in spinach occurred regardless of the photoperiod, and that a longer photoperiod promoted flower bud development. The longer flower stalk length in plants grown in a 15-h photoperiod prior to exposure to natural short photoperiods $(11 \mathrm{~h})$ indicates an effect of the long photoperiod during transplant production. The critical photoperiod for bolting in this cultivar was longer than $13 \mathrm{~h}$ and shorter than $15 \mathrm{~h}$. Because plants that were exposed to a 15-h photoperiod during transplant production and then grown under an 11-h short photoperiod bolted, bolting, like flower bud development, is considered to be an irreversible process.

The significant effect of photoperiod prior to transplanting on flower stalk length in plants subsequently grown under artificial light presumably indicates that $15 \mathrm{~h}$ is longer than the critical photoperiod during transplant production, while 11 and $13 \mathrm{~h}$ are shorter than the critical photoperiod. Plants in the latter treatments were exposed to long photoperiod only after transplanting. Kim et al. (2000) reported that flower bud development was accelerated when spinach plants were grown under a long photoperiod. Since the flower stalk length was greater in plants grown in a 13-h than in an 11h photoperiod prior to transfer to a 16-h photoperiod, the more advanced flower buds that developed in longer photoperiods produced longer flower stalks at harvest. However, more experiments are needed to clarify the relationship between the stages of flower bud development of the transplants and flower stalk length.

Flower stalk length was $70 \mathrm{~mm}$ in plants initially grown in a 15 -h photoperiod, then exposed to artificial light with a 16-h photope- 

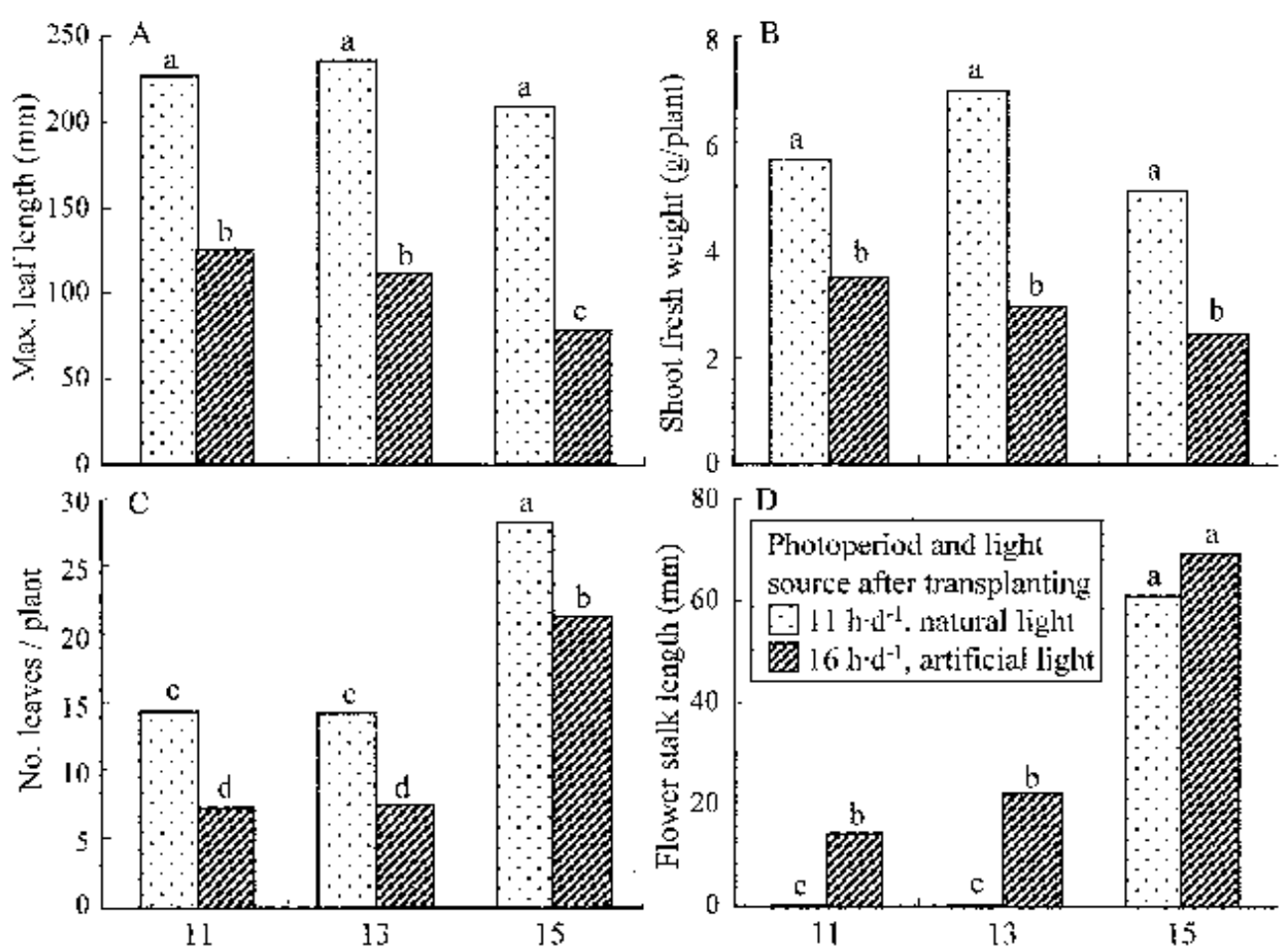

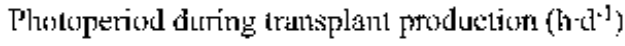

Fig. 2. Effects of photoperiod during leaf transplant production and photoperiod and light source after transplanting on (A) the maximum leaf length, (B) shoot fresh weight, $(\mathbf{C})$ number of leaves, and (D) flower stalk length of spinach plants at harvest. Mean separation by Duncan's multiple range test, $P \leq 0.05$.

riod, vs. only $61 \mathrm{~mm}$ in similar plants grown in natural light with an 11-h photoperiod. Long photoperiod and/or high temperature after transplanting apparently promoted flower stalk elongation. However, the effects on flower stalk length of temperature and photoperiod after transplanting could not be separated in this experiment.

Spinach plants of many oriental cultivars tend to bolt and to lose their economic value at harvest when grown under a long photoperiod. The present results show that bolting can be prevented by using artificial lighting to shorten the photoperiod during transplant production. This manipulation of photoperiod has practical value in spinach production where transplants produced under artificial light are transferred to a greenhouse with natural light.

To better understand bolting and flowering physiology and to apply this knowledge to the production of value-added spinach transplants, further studies are needed on how bolting is affected by photo- and dark periods and air temperature during transplant production. The technique developed for spinach transplant production might be applied to similar systems producing transplants of lettuce (Lactuca sativa L.) and other leafy vegetables that are prone to bolt, and for other vegetables and ornamental plants in which bolting affects economic value.

\section{Literature Cited}

Boswell, R. 1935. Studies of the temperature, day length and development interrelations of spinach variety in the field. Proc. Amer. Soc. Hort. Sci. 32:549-557.

Buwalda, F., R. Baas, and P.A. van Weel. 1994. A soilless ebb-and-flow system for all-year-round chrysanthemums. Acta Hort. 361:123-132.

Cooper, A.J. 1973. Rapid turn-round is possible with experimental nutrient film technique. The Grower, 5 May 1973, p. 1048-1051.

Chun, C., T. Kozai, C. Kubota, and K. Okabe. 2000. Manipulation of bolting and flowering in a spinach (Spinacia oleracea L.) transplant production system using artificial light. Acta Hort. 515:201-206.

Eguchi, T. and H. Ichikawa. 1940. Studies on the flower bud development and bolting of spinach (in Japanese). J. Jpn. Soc. Hort. Sci. 11:13-56.

Fredericq, H. 1964. Conditions determining effects of far-red and red irradiations on flowering response of Pharbitis nil. Plant Physiol. 39:812816.

Garner, W.W. and H.A. Allard. 1920. Effect of the relative length of day and night and the factors of the environment upon growth and reproduction in plants. J. Agr. Res. 18:553-606.

Hartmann, H.T., A.M. Kofranek, V.E. Rubatzky, and W.J. Flocker. 1988. Plant science. PrenticeHall, Englewood Cliffs, N.J.

Kagawa, A. 1997. Physiology in cultivation of highquality spinach (in Japanese). Ishizue Publishers, Tokyo.

Kim, H-.H., C. Chun, T. Kozai, and J. Fuse. 2000. The potential use of photoperiod during transplant production under artificial lighting condi- tion on floral development and bolting, using spinach as a model. HortScience 35:43-45.

Kitaya, Y., G. Niu, T. Kozai, and M. Ohashi. 1998. Photosynthetic photon flux, photoperiod, and $\mathrm{CO}_{2}$ concentration affect growth and morphology of lettuce plug transplants. HortScience 33:988-991.

Knott, J.E. 1932. Rapidity of response of spinach to a change in photoperiod. Plant Physiol. 7:125130.

Knott, J.E. 1934. Effect of localized photoperiod on spinach. Proc. Amer. Soc. Hort. Sci. 31:152-154.

Kozai, T. 1998. Transplant production under artificial light in closed systems, p. 296-308. In: Proc. 3rd Asian Crop Sci. Conf., Taiwan, Rep. of China.

Magruder, R. and H.A. Allard. 1936. The effect of controlled photoperiod on the production of seed stalks in eight varieties of spinach. Proc. Amer. Soc. Hort. Sci. 34:502-506.

Metzger, J.D. and J.A.D. Zeevaart. 1980. Effect of photoperiod on the levels of endogenous gibberellins in spinach as measured by combined gas chromatography-selected ion current monitoring. Plant Physiol. 66:844-846.

Salisbury F.B. 1965. Time measurement and light period in flowering. Planta 66:1-26.

Singhal, R.S. and P.R. Kulkarni. 1998. Leafy vegetables, p. 533-588. In: D.K. Salunkhe and S.S. Kadam (eds.). Handbook of vegetable science and technology: Production, composition, storage, and processing. Marcel Dekker, New York.

Zeevaart, J.A.D. 1971. Effects of photoperiod on growth rate and endogenous gibberellins in the long day rosette spinach. Plant Physiol. 47:821827. 